\title{
Estimating the snake species richness of the Santubong Peninsula (Borneo) in two different ways
}

\author{
Johan van Rooijen ${ }^{1,2,3}$ \\ ${ }^{1}$ Zoological Museum Amsterdam, Mauritskade 61, 1092 AD Amsterdam, The Netherlands \\ ${ }^{2}$ Tulpentuin 313, 2272 EH Voorburg, The Netherlands \\ ${ }^{3}$ E-mail:jl.van.rooijen@hetnet.nl
}

Key words: Chao I estimator, negative exponential function, rarefaction curve, Santubong Peninsula Borneo, snakes, species richness, Weibull function

\begin{abstract}
The distribution of Borneo's species across the island is far from well-known. This is particularly true for snakes which are hard to find. Given the current rate of habitat destruction and consequent need for conservation strategies, more information is required as to the species composition and richness of specific areas of potential conservation priority. An example is the Santubong Peninsula, Sarawak, Malaysia, part of which has recently been gazetted as a National Park. In this paper, the snake species richness of the Santubong Peninsula is estimated on the basis of data obtained during 450 survey-hours. Thirty-two species were recorded. Negative exponential and Weibull functions were fitted to the rarefaction curve. The Weibull function exhibited a high goodness-of-fit, as opposed to the negative exponential function. On the basis of the fitted Weibull function, the total number of snake species was estimated to be 42 . A similar estimate of 40 was obtained by applying the nonparametric Chao I estimator. Thus, less than a third of Borneo's known 139 land snakes inhabit the Santubong Peninsula. Extrapolation of the fitted Weibull function demonstrated that direct measuring of herpetofaunal species richness of species-rich tropical ecosystems is unfeasible given the required search time. I advocate that the use of estimates is unavoidable.
\end{abstract}

\section{Contents}

Introduction 141

Material and methods ……………

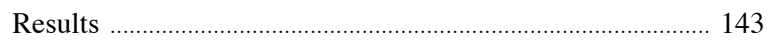

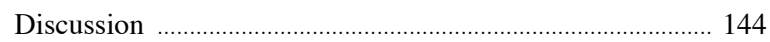

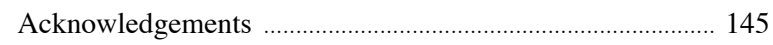

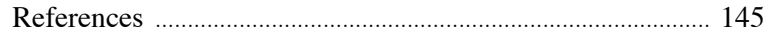

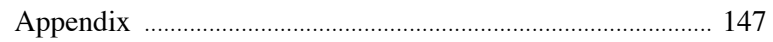

\section{Introduction}

Herpetological surveys of tropical ecosystems have, almost without exception, a common denominator: they result in incomplete inventories in spite of sub- stantial investments in terms of search effort. This is particularly true for snakes which are hard to find (e.g. Lloyd et al., 1968; Inger and Colwell, 1977; Hofer and Bersier, 2001; Orlov et al., 2003). As a consequence, estimation techniques are of interest when the intended objective is to assess species richness, an elementary criterion conservationists may use when identifying priority areas. One such estimation technique consists of extrapolating the species accumulation curve. Species accumulation curves are regularly applied in herpetofaunal surveys, but they are mostly used to arrive at qualitative judgements about the exhaustiveness of the survey (e.g. Murphy et al., 1994; Zug et al., 1998; Ziegler, 2002). However, extensive and sophisticated literature exists pertaining to methods and models used to quantitatively estimate species richness, on the basis of either rarefied species accumulation curves or abundance patterns (e.g. Colwell and Coddington, 1994; Flather, 1996; Longino et al., 2002; Brose et al., 2003). In this paper, two of those techniques are used to estimate the snake species richness of the Santubong Peninsula, Borneo.

Borneo, covering a land area of approximately $743.380 \mathrm{~km}^{2}$, constitutes the largest island of the IndoMalayan Archipelago. Its herpetofauna is relatively well studied and the accumulated information is very suitable for biogeographic studies entailing comparisons between landmasses (e.g. Inger and Voris, 2001). However, at the spatial scale which is relevant for conservation, much needs to be learned. As for snakes, the distribution of many species is poorly known (e.g. Stuebing and Inger, 1998) and it is uncertain whether Borneo's protected areas encompass the majority of species (Stuebing and Inger, 1999). For example, the number of snakes known to inhabit the popular Bako National Park is just 11 (Das and Charles, 1993a) and the number recorded in Lambir Hills National Park is 
only ten (Das and Charles, 1993b; Hazebroek and Morshidi, 2001). Actually, no efforts have been undertaken to estimate the snake species richness of such areas.

The Santubong Peninsula covers approximately 38 $\mathrm{km}^{2}$ and is situated $25 \mathrm{~km}$ north of Kuching, Sarawak, Malaysia. Mount Santubong (810 metres above sea level) constitutes the highest point. The mountainous part of the Santubong Peninsula is covered with mature lowland dipterocarp rainforest and hill dipterocarp rainforest. Pockets of kerangas forest exist locally within the lowland forest. The peninsula experiences a comparatively high annual rainfall (Seal, 1958; Hazebroek and Marshidi, 2001) and many streams traverse the lowland forest. Mangrove-swamp and palm-swamp areas are situated in the southern areas and along the Sarawak River, which borders a part of the peninsula. Mount Santubong has been a proposed national park for some years (Hazebroek and Morshidi, 2001). Recently however, it has been gazetted as a national park (Borneo Post).

\section{Material and methods}

Three collection methods were applied. The first, and predominantly applied, method corresponds to visual encounter survey (VES), a simple method which has been shown to be effective for surveying rainforest herpetofauna (Doan, 2003). VES was carried out both during day and night (e.g. Coddington et al., 1996; Doan, 2003). Existing trails were used in an altitudinal range of 0-500 $\mathrm{m}$ and with a total length of $5 \mathrm{~km}$. These trails traversed hill dipterocarp forest, lowland dipterocarp forest, kerangas forest and cultivated areas and provided ample access to forest streams. The second collection method consisted of searching for road-kills along the length of the peninsula. The third entailed turning logs, fallen tree bark and similar objects in order to uncover snakes hiding underneath. Sampling effort was expressed in terms of search days where one search day was defined as roughly 4.5 search hours. Specimens were identified and photographed but were not collected, with the exception of nearly undamaged road victims. Voucher photographs were deposited in the Universiti Kebangsaan Malaysia Digital Photograph Collection (UKMDPC). Several road-killed voucher specimens were deposited in the collection of the National Museum of Natural History, Leiden, The Netherlands (RMNH). The total sampling effort equalled 98 search days which were invested during seven sur- veys carried out in the period 2001-2008, three in September/October and four in March/April.

A rarefaction curve was made by generating 20 random permutations of the search days and constructing an average species accumulation curve (Colwell and Coddington, 1994). Two models were fitted to the rarefaction curve. The first model corresponds with a negative exponential model (Colwell and Coddington, 1994; Flather, 1996). It can be derived as follows: A is the total number of species present in the area under investigation and $\mathrm{Y}$ is the total number of species found. The number of new species found per search day is assumed to be proportional to the number of as yet undiscovered species:

$$
\frac{d Y}{d t}=c(A-Y)
$$

which can be rewritten as

$$
\frac{1}{A-Y} d Y=c d t
$$

with $c=a$ constant that denotes the ease with which snakes are found. The expression can be integrated on both sides:

$$
\begin{gathered}
\int_{0}^{Y} \frac{1}{A-Y} d Y=\int_{0}^{t} c d t \\
\text { which leads to } \\
Y=A\left(1-\frac{1}{e^{c t}}\right)
\end{gathered}
$$

This is the negative exponential.

A possible disadvantage of this model is the assumption that all species are found with the same ease (denoted with the parameter $c$ ). This may be an oversimplification as some species may occur in lower densities. Indeed, species abundance patterns generally correspond to a log-normal distribution with some species being abundant and many being rare (e.g. Lloyd et al., 1968; Coddington et al., 1996; Limpert et al., 2001; Longino et al., 2002). This also appears to apply to the snake community of the Santubong Peninsula (Van Rooijen and Van Rooijen, 2007). To account for progressively lower detection chances, the model can be refined substantially by adding two parameters ( $d$ and $p$ ) as follows:

$$
Y=A\left(1-\frac{1}{e^{(\alpha t-d))^{p}}}\right) .
$$

This is known as the Weibull function. 
The Weibull function has been shown to exhibit a good fit in studies of avian diversity (Flather, 1996) and diversity of small reptiles (Thompson et al., 2003). Both the negative exponential and the Weibull model were fitted to the data using nonlinear regression analysis (e.g. Norusis and SPSS, 1993) with SPSS (release 14 February 1996; SPSS Inc.). The appropriateness of the models was evaluated on the basis of goodness-of-fit.

As the performance of the various richness estimators has not yet been thoroughly studied, Veith et al. (2004) recommend the simultaneous use of different estimators. Therefore, the 'Chao I' estimator (Chao, 1984; Coddington et al., 1996; Hofer and Bersier, 2001) was also applied in order to check for large discrepancies with the estimate based on the rarefaction curve. The estimator is based on the observed number of rare species,

$$
A=Y+\left(a^{2} / 2 b\right)
$$

where $A$ is the total number of species, $Y$ is the observed number of species, $a$ is the number of observed
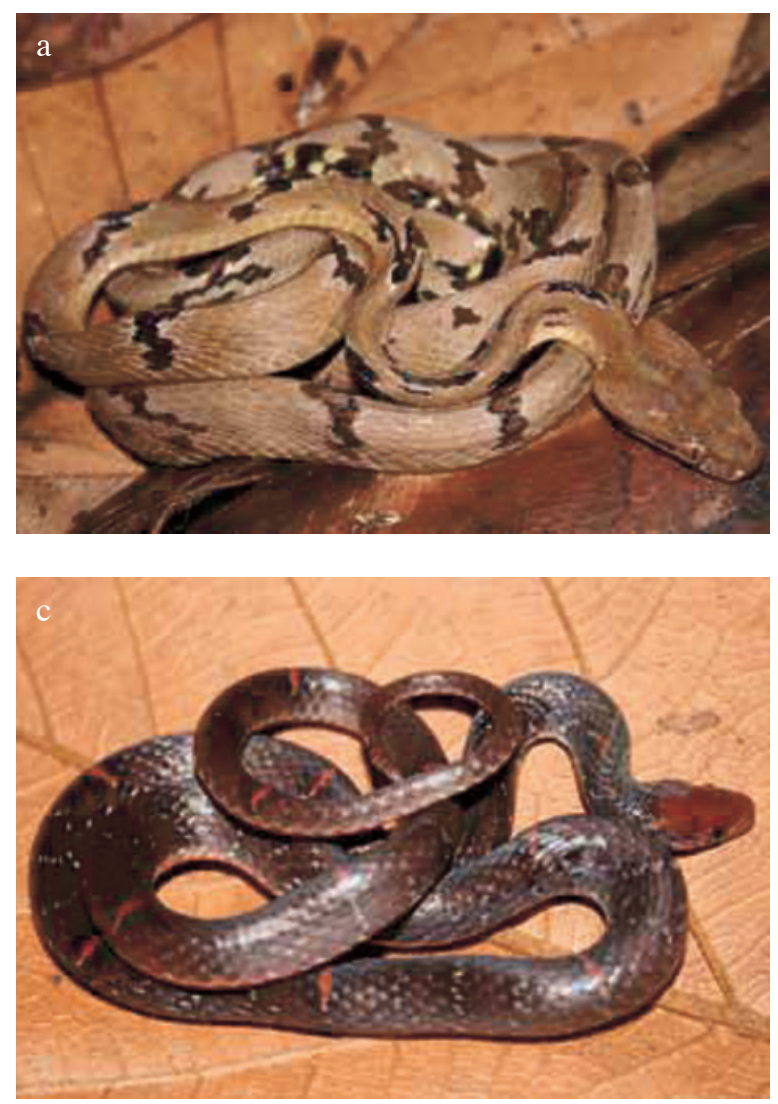

species represented by a single specimen and $b$ is the number of observed species represented by exactly 2 specimens.

\section{Results}

A total number of 98 search days yielded 175 snakes, representing 32 species. In terms of eco-functional types (habitat + circadian habits), 11 species were arboreal, four (semi-)aquatic, eight (semi-)fossorial and nine terrestrial. Fourteen species were nocturnal and 18 diurnal. As such, the applied search strategy appears to have sufficiently accessed the full breadth of ecological types. Nine species each were represented by a single specimen and six by two specimens. An updated list of snake species recorded from the Santubong Peninsula is given in the Appendix. The table includes some species recorded in other studies. For illustrations of some of the recorded species see Figure 1 while for photographic records of other species see Van Rooijen and Van Rooijen (2004, 2007).
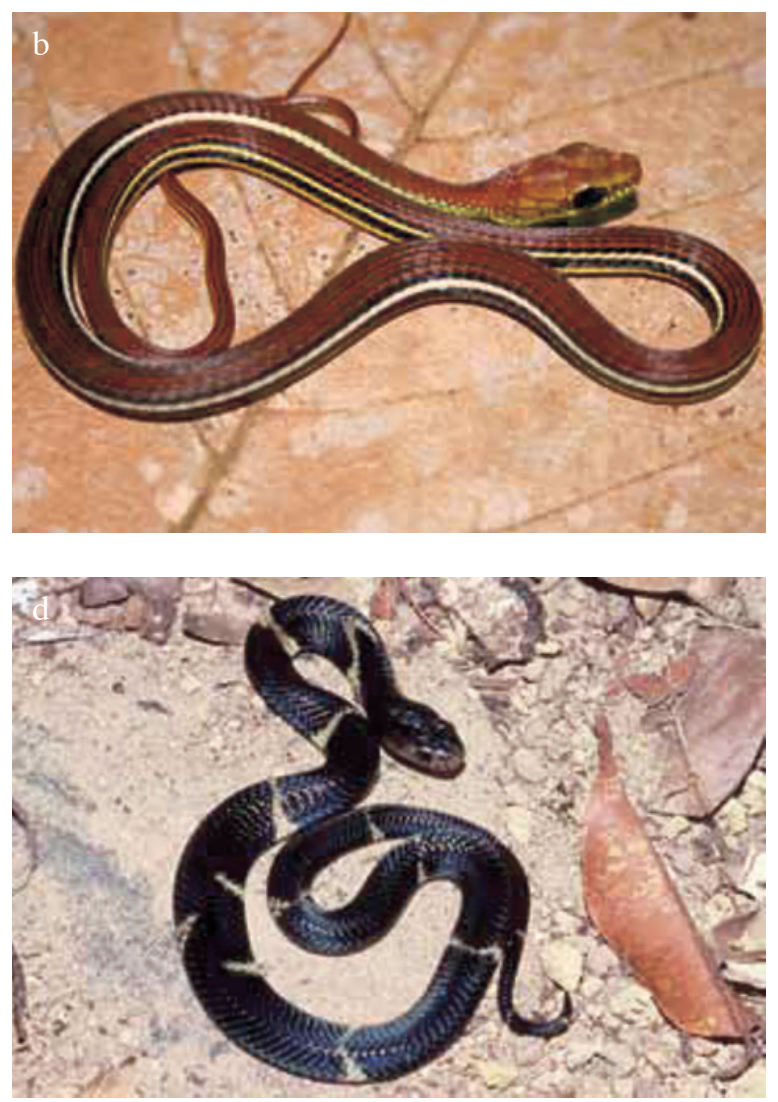

Fig. 1a-d. Illustrations of some of the recorded species. a: Boiga cynodon, subadult; b: Dendrelaphis caudolineatus, juvenile; c: Oligodon subcarinatus, adult; d: Naja sumatrana, juvenile. 
Figure 2 depicts the rarefaction curve as well as the fitted negative exponential and Weibull functions. As expected, the negative exponential exhibits a lower goodness-of-fit. At first, the fitted curve is situated beneath the rarefaction curve, then slightly above and finally it drops beneath the rarefaction curve again. The suboptimal fit of the negative exponential as well as the pattern of residuals (deviations of the model from the rarefaction curve) are in agreement with results obtained with regard to avian diversity (Flather, 1996). The Weibull function on the other hand, exhibits a nearperfect fit which is also in accordance with results obtained by Flather (1996). Therefore, the fitted Weibull function may be assumed to offer the most realistic approach to the species accumulation process. The asymptote of the fitted equation equals 42 . As such, a total of 42 snake species is estimated to inhabit the Santubong Peninsula on the basis of the fitted Weibull function. Application of the Chao I estimator resulted in an estimate of 40 , a figure that is reasonably similar and therefore does not cast doubt on the Weibull-estimate. Taking the average of both estimates, 41 species are estimated to inhabit the Santubong Peninsula.

\section{Discussion}

Inger (2003) and Voris (2006) stressed the importance of sampling methodology when estimating biodiversity. In particular, sufficient sampling coverage through both time and space is required to avoid underestimation of species richness. The estimates obtained in this study may be downwardly biased as a result of suboptimal sampling methods. For instance, although searches were carried out during both day and night, no searches were performed late at night or in the early morning (before dawn). In addition, sampling of canopy microhabitat was obviously unfeasible. Therefore, the plausibility of the obtained estimate of 41 snake species was assessed by comparing it with the species richness recorded by Lloyd et al. (1968) in a lowland rainforest of Sarawak with comparable surface area. Lloyd et al. invested thousands of man-hours. As such, their inventory can be assumed to be complete. They recorded 47 snake species, a figure that is slightly higher than, but still very similar to, the aforementioned estimate for the Santubong Peninsula. In conclusion, the richness estimate obtained in this study probably underestimates the true species richness, although not to a great extent.

Approximately 139 landsnake species are known from Borneo (Malkmus et al., 2002; Das, 2006). This is a downwardly biased figure however, as new species are still being recorded. For example, the recent descriptions of two new colubrid snakes, Dendrelaphis haasi Van Rooijen and Vogel, 2008 and Dendrelaphis kopsteini Vogel and Van Rooijen, 2007 (first record for Borneo provided by Das (2007)), have increased the number of Bornean species to 139. If the estimated total of 41 snake species is reasonably ac-

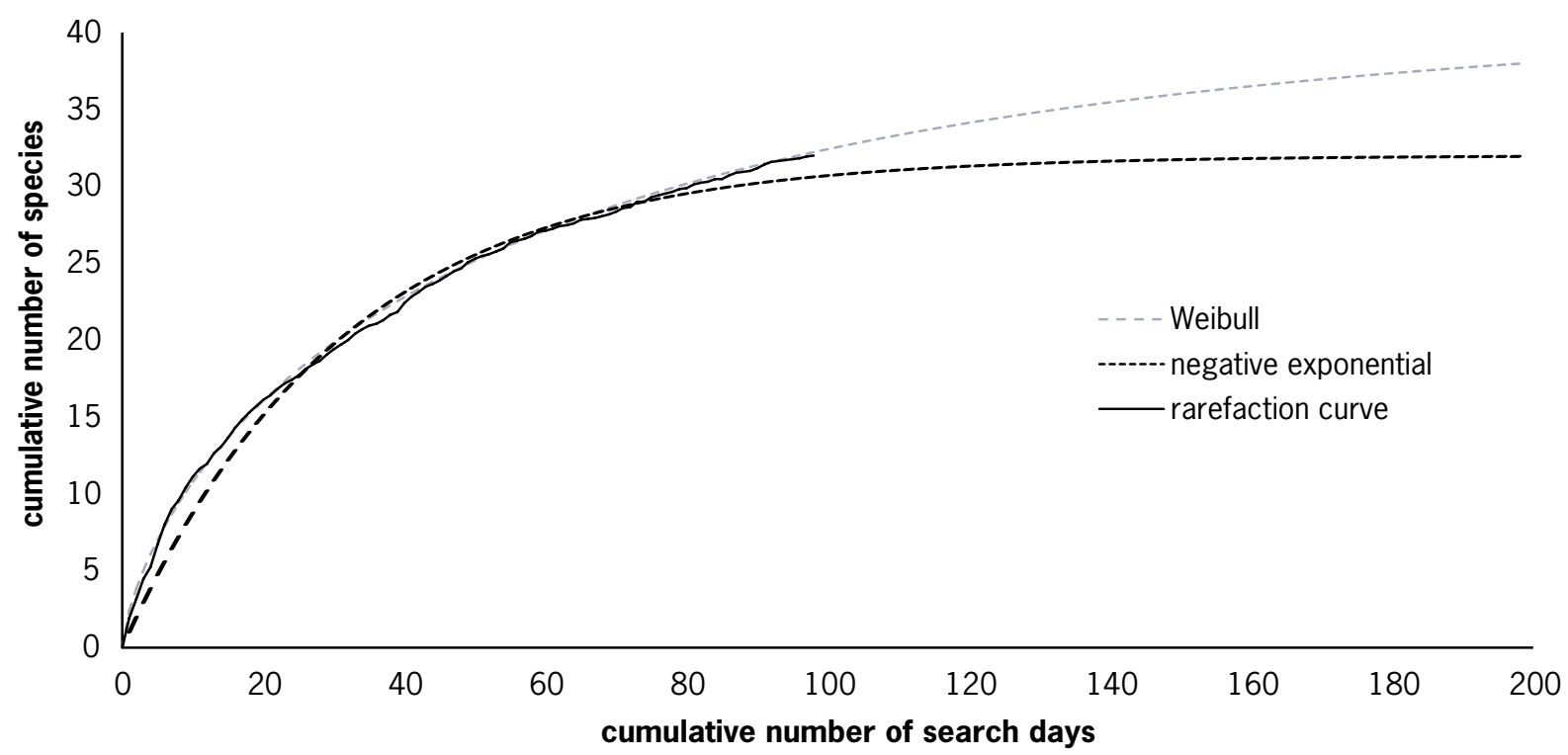

Fig. 2. Snake species rarefaction curve with fitted negative exponential and Weibull function. The fitted functions have been extrapolated to 200 search days. The fit of the negative exponential function is suboptimal whereas the fit of the Weibull function is near-perfect. 
curate, the Santubong Peninsula harbours fewer than a third of Borneo's snakes. This finding underscores the fact that Borneo's species are not distributed uniformly across this magnificent island. Thus, care should be taken to select conservation areas in a way that preserves the full range of species (e.g. Lombard et al., 1995).

Ideally, one wants to measure directly, instead of estimate, the snake species richness of any area of conservational interest by surveying until completion. Then the exact species composition would also be known, information that obviously has added value. However, extrapolation of the rarefaction curve on the basis of the fitted Weibull function (Fig. 2) provides a rather discouraging prospect: investing another 100 search days will yield merely six additional snake species, a return on investment that no herpetologist would consider alluring. Thus, when it comes to herpetofaunal communities in tropical ecosystems, using richness-estimates will be inevitable in the vast majority of cases.

\section{Acknowledgements}

I wish to thank three anonymous reviewers for their critical and constructive comments which contributed to the honing of the final text. Thanks to Gernot Vogel and Chan Kin Onn for reviewing an earlier version of the manuscript. Finally, I express my gratitude to my wife Myriam and my daughter Mia for putting up with my unsatiable hunger to explore the herpetological wonders of the rainforest.

\section{References}

Brose U, Martinez ND, Williams RD. 2003. Estimating species richness: sensitivity to sampling coverage and insensitivity to spatial patterns. Ecology 84: 2364-2377.

Chao A. 1984. Non-parametric estimation of the number of classes in a population. Scandinavian Journal of Statistics 11: 265-270.

Coddington JA, Young LH, Coyle FA. 1996. Estimating spider species richness in a southern Appalachian cove hardwood forest. The Journal of Arachnology 24: 111-128.

Colwell RK, Coddington JA. 1994. Estimating terrestrial biodiversity through extrapolation. Philosophical Transactions of the Royal Society of London 345: 101-118.

Das I. 2006. A photographic guide to snakes and other reptiles of Borneo. London: New Holland Publishers.

Das I. 2007. Dendrelaphis kopsteini (Kopstein's Bronzeback Tree Snake). Geographic Distribution. Herpetological Review 38: 220.

Das I, Charles JK. 1993a. A contribution to the herpetology of Bako national park, Sarawak, East Malaysia. Hamadryad 18: 24-27.
Das I, Charles JK. 1993b. Amphibians and reptiles recorded from the Lambir Hills national park, Sarawak, East Malaysia. Hamadryad 18: 17-23.

Denzer W. 1996. Reptilien und Amphibien der Santubong Halbinsel, Sarawak, Borneo. Sauria 18: 35-42, 20: 32.

Doan TM. 2003. Which methods are most effective for surveying rainforest herpetofauna? Journal of Herpetology 37: 7281.

Flather CH. 1996. Fitting species-accumulation functions and assessing regional land use impacts on avian diversity. Journal of Biogeography 23: 155-168.

Hazebroek HP, Morshidi AKA. 2001. National parks of Sarawak. Kota Kinabalu: Natural History Publications, Borneo.

Hofer U, Bersier L-F. 2001. Herpetofaunal diversity and abundance in tropical upland forests of Cameroon and Panama. Biotropica 33: 142-152.

Inger RF. 2003. Sampling biodiversity in Bornean frogs. The Natural History Journal of Chulalongkorn University 3: 9-15.

Inger RF, Colwell RK. 1977. Organization of contiguous communities of amphibians and reptiles in Thailand. Ecological Monographs 47: 229-253.

Inger RF, Voris HK. 2001. The biogeographical relations of the frogs and snakes of Sundaland. Journal of Biogeography 28: 863-891.

Limpert E, Stahel WH, Abbt M. 2001. Log-normal distributions across the sciences: keys and clues. Bioscience 51: 341-352.

Lloyd M, Inger RF, King FW 1968. On the diversity of reptile and amphibian species in a Bornean rain forest. The American Naturalist 102: 497-515.

Lombard AT, Nicholls AO, August PV. 1995. Where should nature reserves be located in South Africa? A snake's perspective. Conservation Biology 9: 363-372.

Longino JT, Coddington J, Colwell RK. 2002. The ant fauna of a tropical rainforest: estimating species richness three different ways. Ecology 83: 689-702.

Malkmus R, Manthey U, Vogel G, Hoffmann P, Kosuch J. 2002. Amphibians and reptiles of Mount Kinabalu (North Borneo). Ruggel: A.R.G. Gantner Verlag K.G.

Murphy JC, Voris HK, Karns DL. 1994. A field guide to the snakes of the Danum Valley, a Bornean tropical rainforest ecosystem. Bulletin of the Chicago Herpetological Society 29: 133-151.

Norusis and SPSS Inc. (1993). SPSS Advanced Statistics, Chicago: SPSS.

Orlov NL, Ryabov SA, Nguyen Van Sang, Nguen Quang Truong 2003. New records and data on the poorly known snakes of Vietnam. Russian Journal of Herpetology 10: 217-240.

Seal J. 1958. Rainfall and sunshine in Sarawak. Sarawak Museum Journal 8: 500-544.

Stuebing RB. 1991. A checklist of the snakes of Borneo. Raffles Bulletin of Zoology 39: 323-362.

Stuebing RB. 1994. A checklist of the snakes of Borneo. Addenda and corrigenda. Raffles Bulletin of Zoology 42: 931936.

Stuebing RB, Inger RF. 1998. Additional records on two rare snakes from Borneo, with the confirmation of Trimeresurus malcolmi LOVERIDGE as a distinct species. Raffles Bulletin of Zoology 46: 325-328.

Stuebing RB, Inger RF. 1999. A field guide to the snakes of Borneo. Kota Kinabalu: Natural History Publications, Borneo. 
Thompson GG, Withers PC, Pianka ER, Thompson SA. 2003. Assessing biodiversity with species accumulation curves; inventories of small reptiles by pit-trapping in Western Australia. Austral Ecology 28: 361-383.

Van Rooijen J, Van Rooijen M. 2004. Einige Beobachtungen zur terrestrischen Schlangenfauna auf der Halbinsel Santubong, Sarawak, Ost-Malaysia. Sauria 26: 19-28.

Van Rooijen J, Van Rooijen M. 2007. The landsnakes of the Santubong Peninsula, Sarawak, Borneo: a preliminary list of species with natural history notes. Russian Journal of Herpetology 14: 27-38.

Van Rooijen J, Vogel G. 2008. A review of the Dendrelaphis pictus complex (Serpentes: Colubridae) - I: description of a sympatric species. Amphibia-Reptilia 29: 101-115.

Veith M, Lötters S, Andreone F, Rödel M-O. 2004. Measuring and monitoring Amphibian diversity in tropical forests. II. Estimating species richness from standardized transect censing. Ecotropica 10: 85-99.
Vogel G, Van Rooijen J. 2007. A new species of Dendrelaphis (Serpentes: Colubridae) from Southeast Asia. Zootaxa 1394: 25-45.

Voris HK. 2006. Assessment of biodiversity among Southeast Asian amphibians and reptiles. The Natural History Journal of Chulalangkorn University 6: 1-10.

Ziegler T. 2002. Die Amphibien und Reptilien eines Tieflandfeuchtwald-Schutzgebietes in Vietnam. Münster: Natur und Tier Verlag.

Zug GR, Win H, Thin T, Min TZ, Lhon WZ, Kyaw K. 1998. Herpetofauna of the Chatthin Wildlife Sanctuary, NorthCentral Myanmar with preliminary observations of their natural history. Hamadryad 23: 111-120.

Received: 28 May 2009

Accepted: 20 August 2009

Published online: 5 November 2009

Editor: J.W. Arntzen 


\section{Appendix}

List of snake species recorded from the Santubong Peninsula. References: 1: Stuebing (1991, 1994); 2: Denzer (1996); 3: Van Rooijen and Van Rooijen (2004,
2007); 4: this report. Common names were taken from the TIGR Reptile Database (http://www.reptile-database.org, release 18 January 2009).

\begin{tabular}{|c|c|c|c|}
\hline Scientific name & Common name & References & Voucher photographs or specimens \\
\hline \multicolumn{4}{|l|}{ Colubridae } \\
\hline Ahaetulla prasina Boie, 1827 & Oriental Whip Snake & 3,4 & UKMDPC 10125 \\
\hline Amphiesma sarawacense (Günther, 1872) & Sarawak Keelback & 3 & UKMDPC 10131 \\
\hline Asthenodipsas laevis (Boie, 1827) & Smooth Slug Snake & 3,4 & UKMDPC 10111 \\
\hline Boiga cynodon (Boie, 1827) & Dog-toothed Cat Snake & 1,4 & UKMDPC 10126 \\
\hline Boiga dendrophila annectens (Boie, 1827) & Mangrove Cat Snake & 1,3 & UKMDPC 10132 \\
\hline Calamaria borneensis Bleeker, 1860 & Borneo's Dwarf Snake & 3 & \\
\hline Calamaria leucogaster Bleeker, 1860 & Ampat Lawang Dwarf Snake & 1,3 & UKMDPC 10133 \\
\hline Calamaria lumbricoidea Boie, 1827 & Variable Reed Snake & 3 & UKMDPC 10112 \\
\hline Cerberus rynchops (Schneider, 1799) & Dog-faced Water Snake & 1 & \\
\hline Chrysopelea paradisi Boie, 1827 & Paradise Tree Snake & 3,4 & UKMDPC 10127 \\
\hline Dendrelaphis caudolineatus (Gray, 1834) & Striped Bronzeback & 3,4 & UKMDPC 10128 \\
\hline Dendrelaphis pictus (Gmelin, 1789) & Painted Bronzeback & 1,3 & UKMDPC 10134 \\
\hline Dendrelaphis formosus (Boie, 1827) & Elegant Bronzeback & 3,4 & UKMDPC 10129 \\
\hline Dryophiops rubescens (Gray, 1835) & Brown Whip Snake & 3,4 & UKMDPC 10124 \\
\hline Fordonia leucobalia (Schlegel, 1837) & Crab-eating Water Snake & 1 & \\
\hline Gonyosoma oxycephalum (Boie, 1827) & Red-tailed Green Rat Snake & 1,3 & UKMDPC 10116 \\
\hline Homalopsis buccata (Linnaeus, 1758) & Puff-faced Water Snake & 1 & \\
\hline Liopeltis tricolor (Schlegel, 1837) & Malayan Ringneck & 3 & UKMDPC 10122 \\
\hline Oligodon octolineatus (Schneider, 1801) & Eight-striped Kukri Snake & $1,3,4$ & UKMDPC 10118 \\
\hline Oligodon purpurascens (Schlegel, 1837) & Brown Kukri Snake & 3 & UKMDPC 10113 \\
\hline Oligodon subcarinatus Günther, 1872 & Beautiful Kukri Snake & 4 & UKMDPC 10140 \\
\hline Pseudorabdion longiceps (Cantor, 1847) & Dwarf Reed Snake & 3 & UKMDPC 10136 \\
\hline Ptyas fuscus (Günther, 1858) & White-bellied Rat Snake & 3 & UKMDPC 10137 \\
\hline Rhabdophis conspicillatus (Günther, 1872) & Red-bellied Keelback & 3 & UKMDPC 10123 \\
\hline Sybinophis cf. melanocephalus (Gray, 1834) & Malayan Many-tooth Snake & 3 & RMNH40090 \\
\hline Xenochrophis maculatus (Edeling, 1865) & Spotted Keelback & 3 & UKMDPC 10110 \\
\hline Xenochrophis trianguligerus (Boie, 1827) & Triangle Keelback & 3 & UKMDPC 10130 \\
\hline \multicolumn{4}{|l|}{ Crotalidae } \\
\hline Tropidolaemus subannulatus (Gray, 1842) & North Philippine Temple Pitviper & $2,3,4$ & UKMDPC 10138, UKMDPC 10114 \\
\hline \multicolumn{4}{|l|}{ Elapidae } \\
\hline Bungarus fasciatus (Schneider, 1801) & Banded Krait & 4 & UKMDPC 10115 \\
\hline Calliophis intestinalis thepassi (Bleeker, 1859) & Banded Malaysian Coral snake & $1,3,4$ & UKMDPC 10139, RMNH 40097 \\
\hline Naja sumatrana (Müller, 1887) & Equatorial Spitting Cobra & 3 & UKMDPC 10117 \\
\hline Ophiophagus hannah (Cantor, 1836) & King Cobra & 3 & UKMDPC 10135 \\
\hline \multicolumn{4}{|l|}{ Pythonidae } \\
\hline Python reticulatus (Schneider, 1801) & Reticulated Python & 3 & UKMDPC 10119 \\
\hline \multicolumn{4}{|l|}{ Typhlopidae } \\
\hline Ramphotyphlops braminus (Daudin, 1803) & Brahminy Blindsnake & 3,4 & RMNH 40091 \\
\hline \multicolumn{4}{|l|}{ Xenopeltidae } \\
\hline Xenopeltis unicolor Reinwardt, 1827 & Sunbeam Snake & 1,3 & UKMDPC 10120 \\
\hline
\end{tabular}

